\title{
Non -human tools for the evaluation of bitter taste in the design and development of medicines: a systematic review
}

\author{
Abeer H. A Mohamed-Ahmed ${ }^{1}$, Jessica Soto ${ }^{1}$, Terry Ernest ${ }^{2}$, Catherine Tuleu ${ }^{1}$, \\ ${ }^{1}$ UCL School of Pharmacy, 29/39 Brunswick Square, WC1N 1AX, London, UK, \\ ${ }^{2}$ GlaxoSmithKline (GSK) Third Ave, Harlow CM19 5AW.
}

\begin{abstract}
Taste evaluation is a critical factor for determining acceptance of medicines by patients. The human taste panel test is the main method used to establish the overall palatability and acceptability of a drug product to a patient towards the end of development. Non human in vitro and in vivo taste evaluation tools are very useful for preformulation, quality control and screening of formulations. These non-human taste assessment tools can be used to evaluate all aspects of taste quality. The focus of this review is bitterness as it is a key aspect of taste in association with the development of medicines. In this review recent in vitro (analytical) and in vivo (nonhuman) tools used are described for the assessment of bitter taste of medicines. Their correlations with human taste data are critically discussed. The potential for their use for early screening of the taste of active pharmaceutical ingredients (API's) to expedite paediatric formulation development is also considered.
\end{abstract}

Keywords. Bitterness, in vitro, in vivo, taste, paediatric and medicine.

\section{Introduction}

The taste of a medicine is a predominant contributor of patient's acceptability and compliance, especially in children. As most drugs have a bitter taste which poses a challenge for development of oral dosage forms, valid taste evaluation methods are needed. The most common method is human taste panel test but its use is restricted by ethical and safety concerns especially when testing drugs with limited toxicity data $[1,2]$. Several direct in vitro and in vivo taste evaluation methods have been reported such as the animal behavioural test, electronic taste sensing systems and cell based assays [1, 2]. An indirect taste assessment method such as drug release/dissolution based mainly on quantification of drug concentration can provide supportive information. These methods might have the potential of overcoming challenges associated with human panels. In this review, the in vitro and in vivo methods used for bitter taste evaluation in the pharmaceutical industry are discussed with a view to assess their industrial and regulatory usability.

\section{Literature review and data collection}

\section{Data sources}

Indexed publications were identified by searching Scopus (subject area was limited to pharmacology, toxicology and pharmaceutics), PubMed, Embase and Web of 
Science (subject area was limited to pharmacology and pharmacy). Studies were included if they were published in English and included search terms bitterness, in vitro, in vivo and taste.

\section{Publication selection}

After removing duplicate publications, a step review process was conducted (Figure 1). First publications' abstracts were screened for relevance to taste evaluation (in vitro, in vivo and human). Review publications and cell based studies were excluded. (The authors are aware that a short review on cell based in vitro taste assessment methods is under preparation). Then, selected full texts were screened for relevance. Only taste studies for active pharmaceutical ingredients/or formulations were included. Taste studies using only human taste panels were excluded as well as studies using only drug release/dissolution or electronic sensors but without human taste data. Only in vivo taste studies using unconditioned and not genetically modified animals were included. Non medicinal taste studies (Food and Beverages Industry) were excluded.

\section{Data extraction}

Data extracted were: in vitro/in vivo taste evaluation tools (type and conditions), sample (concentration and preparation), sample analysis (measurement time, $\mathrm{pH}$ and temperature), data analysis and taste results (correlation with human taste panel test).

\section{Data analysis}

The electronic search results were imported into, and then managed and grouped in Endnote (online https://www.myendnoteweb.com).

\section{Selected publications}

This review included only recent publications (2013-2015) of studies assessing taste of pure APIs, formulations, and commercial medicines (with or without taste masking) in vitro and in vivo. Only 43 publications were eligible for inclusion according to selection criteria mentioned above - the various steps are summarised in Figure 1. 


\begin{tabular}{|lr|}
\hline Databases & Hits \\
Scopus & 325 \\
Pubmed & 1049 \\
Embase & 671 \\
Web of Science & 897 \\
Total & $\mathbf{2 9 4 2}$ \\
\hline
\end{tabular}

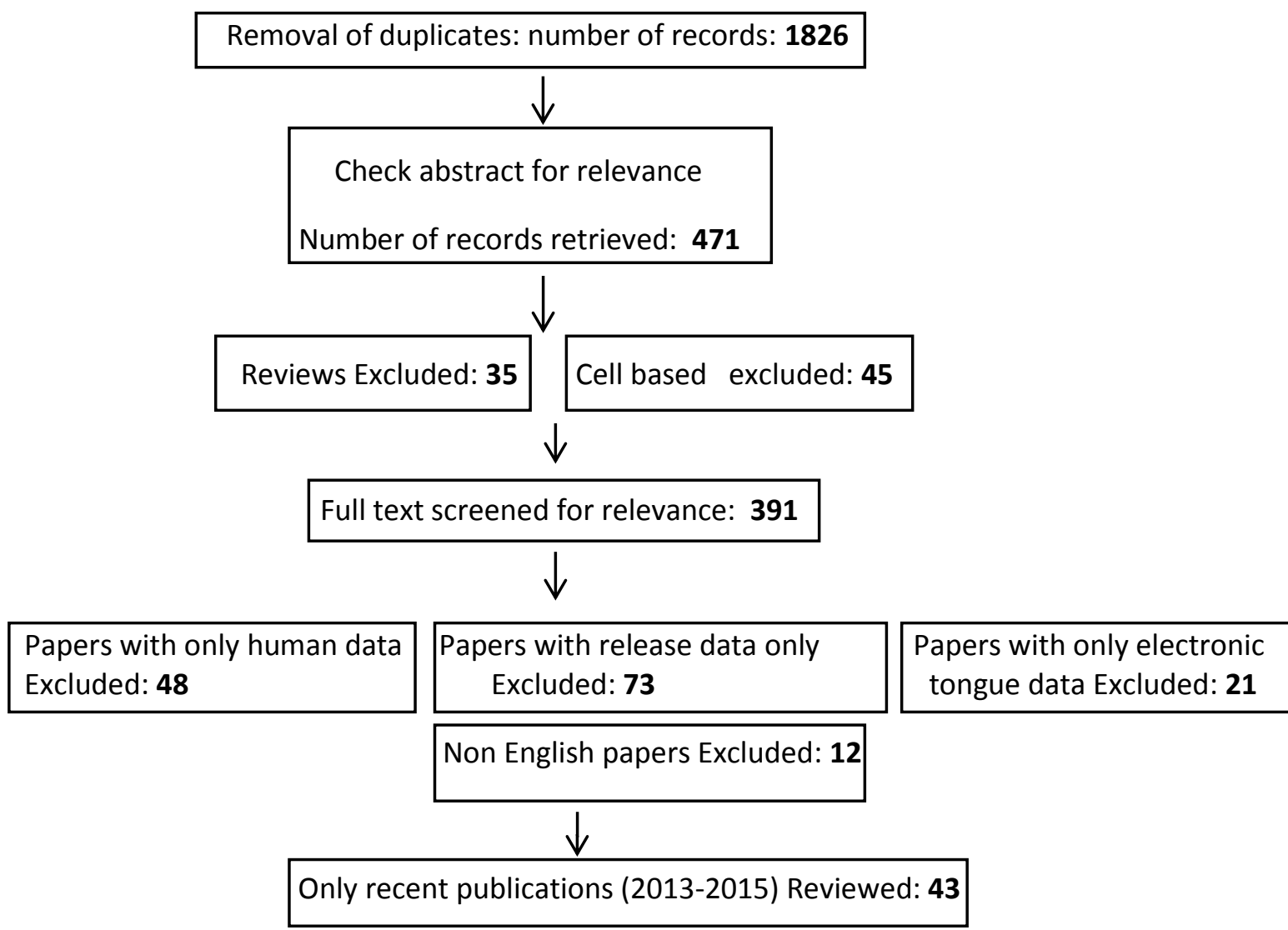

Figure 1. Literature search results for non-human taste assessment tools.

\section{A. In vitro taste evaluation analytical methods}

\section{Electronic taste sensors}

There are several electronic sensors in food and beverages industry using different measurement principles such as voltammetry, potentiometry, impedance, optical techniques and, mass change [1]. The most commonly used Electronic taste sensing systems ('electronic tongues') in the pharmaceutical industry for taste evaluation are: (i) SA401, SA402/ TS-5000z (Insent Inc, Atsugi-Chi, Japan) based on lipid membrane sensors and, (ii) $\alpha$-Astree e-sensor (Alpha M.O.S, Toulouse, France) based on chemical modified field effect technology (ChemFET) with polymeric sensors. Each sensor (undisclosed exact composition) in the Insent electronic sensor is assigned to a specific taste with partial cross selectivity (e.g. AAE for umami, CT0 for saltiness, CAO for sourness, AE1 for astringency and, ACO, ANO and C00 for bitterness), while sensors in the a-Astree electronic sensor are cross 
selective [3]. The a-Astree electronic taste sensing system is composed of seven sensors which differ in composition. Therefore, three types of sets are available: (i) for pharmaceutical application (ZZ, AB, GA, BB, CA, DA and JE), (ii) for food application (ZZ, BA, BB, CA, GA, HA, JB), and (iii) for bitterness intensity measurement of new chemical entities (BD, EB, JA, JG, KA, OA, OB). Selected examples of taste evaluation of pure active pharmaceutical ingredients, preclinical taste masked formulation and commercially available medicines are summarised in Table 1. The operating principle, components and type of sensors and data analysis for these taste sensing systems have been extensively described in other reviews [1, 4]. The Insent system provides information about initial taste (called relative value) and aftertaste (called CPA; Change of membrane Potential caused by Adsorption). a-Astree system measures initial taste only.

As for any analytical tool, the performance of the electronic sensor should be checked to ensure validity of taste data according to the International Conference on Harmonization $(\mathrm{ICH})$ guidelines Q2 [5, 6]. The intra- and inter-day precision of the Insent taste sensing system was investigated within the linearity range $(0.01-100 \mathrm{mM}$ Quinine $\mathrm{HCl})$ [5]. All sensors showed acceptable repeatability $(\mathrm{RSD}<4 \%$ is acceptable and $\mathrm{R}^{2}$ should exceed 0.98 according to $\mathrm{ICH}$ guidlines) except bitterness sensor 3 and the sourness sensor. The inter-day precision was assessed over six months, none of the sensors showed acceptable values (RSD $>4 \%$ ). This suggested that the taste sensing system was susceptible to minor changes in the analytical conditions [5]. Small variations in temperature, $\mathrm{pH}$ and age of sensors can have a large impact on sensor response [5]. It is recommended to have an external standard with known concentration and expected sensor response. This external standard should be tested at the same time as the samples and exposed to the same environment settings as the sample to ensure elimination of these variations. Furthermore, contemporary calibration should be conducted using known concentrations of a single compound close to its concentration in the tested formulation in order to evaluate the results [5].

In the a-Astree electronic taste sensing, each sensor for both sensors sets [set 2 for pharmaceutical industry and set 5 for Food industry] fulfilled the $\mathrm{ICH}$ repeatability requirements for quinine $\mathrm{HCl}(\mathrm{RSD}<2.5 \%)$. Two sensors of set 5 showed more sensitivity to quinine than set 2 . The sensors of set 5 can be used to improve bitterness detection [6]. Only sensors ZZ and JE met the requirement for inter-day precision. Use of an external standard did not improve the inter-day precision [6]. The effect of analytical conditions and sensor age on the performance of the $\alpha$-Astree electronic tongue was not described in the literature. However, some sensors of the a-Astree electronic tongue displayed poor performance after storage for 4 months. The robustness of the $\alpha$-Astree electronic tongue can be checked by constructing calibration curve of a known bitter compound before and after the storage of the sensor $[5,6]$. 
Woertz et al. [3] reported that the Insent electronic tongue was found to provide more reliable (in vitro/in vivo correlation) and precise (reproducibility and repeatability) data than the $\alpha$-Astree electronic tongue. However it is impossible to give an absolute statement regarding the taste of API based on any electronic sensors data only and correlation of these data with human taste panel is required to draw aversiveness conclusions [3]. Both Insent and $\alpha$-Astree can be used for taste assessment of taste masked formulations by comparing its taste to the pure API or the placebo formulations $[3,7,8]$. This can be done by measuring the Euclidian distance between taste masked formulation and either pure drug or placebo (pure taste masking agent) on the principle component analysis (PCA) map [3, 7-9]. The smaller the distance between the formulation and placebo the more effective the taste masking should be. On the contrary the smaller the distance between taste masked formulation and pure drug, the more bitter the formulation and the lower taste masking efficiency [7-9].

\subsection{Correlation between electronic tongues and human taste evaluation of medicine.}

Correlation of taste sensor data and human taste panel results can be done by either using sensor output (relative value or CPA) or predicted bitterness scores obtained from the taste sensor. In the latter, bitterness prediction models are obtained using a standard bitter compound with known human bitterness scores either supplied by the manufacturer or experimentally determined. Inverse calibration model based on partial least square analysis (PLS) have been used as correlation method [9, 10]. The model specifies the relationship between single independent variable (bitterness scores from human taste panel data) with a combination of multiple components of electronic sensors data. The correlation curve can be used to predict bitterness score of each sample [10]. The Euclidean distance between: (1) taste masked formulation and placebo or pure drug and, (2) pure drug and water can also be used to compare electronic tongue data to human taste data $[7,11]$. The conditions used in the taste sensors studies described below are summarised in Table 1.

\subsubsection{Astree electronic tongue}

Several studies showed that taste evaluated using a-Astree electronic tongue correlated well with human taste panels [7-10]. In Wang et al. [10], the sensors were trained with human bitterness scores [ $0=$ not bitter up to $5=$ so bitter] to establish the PLS model. $10 \mathrm{ml}$ of berberine $\mathrm{HCl}$ of different concentrations were held in the mouth for 10 s before spitting out (129 volunteers). Identical samples (1.23, 2.46, 4.92 and $12.30 \mathrm{mg} / \mathrm{ml}$ ) were analysed by electronic tongue. The electronic tongue data matched the human panel data with $\mathrm{R}^{2}$ of 0.99 according to correlation plot (between predicted bitterness scores (electronic sensors) and bitterness scores from human panel) [10]. This curve was used to predict bitterness of berberine $\mathrm{HCl}$. There was no significant difference between bitterness scores predicted from electronic 
tongue data using the correlation plot and bitterness scores from human data $(P>0.05)[10]$.

In study by Ito et al. [9], the predicted bitterness score of $\mathrm{H} 1$-antihistamines was obtained and correlated with those of a panel (actual bitterness score) by using PLS. The samples were tested at $0.1 \mathrm{mM}$ in both electronic tongue and human taste panel test. In human taste panel test (11 volunteers), quinine $\mathrm{HCl}$ was used as the bitterness standard at concentrations of $0.01,0.03,0.10,0.3$ and $1 \mathrm{mM}$ corresponding to bitterness scores of $0,1,2,3$ and 4 respectively. $2 \mathrm{ml}$ of the samples were kept in the mouth for 15s [9]. The electronic sensors ( $A B$ and JE) data fitted the human bitterness scores with $r^{2}$ of 0.9621 . In this case quantitative and qualitative prediction of unknown drug bitterness intensities using electronic sensor was achievable and precise based on the PLS prediction model when used for evaluation of basic bitter drugs such as $\mathrm{H} 1$ antihistamines [9]. Furthermore, the ability of this electronic tongue to assess the taste masking of epinastine $\mathrm{HCl}$ using acesulfame potassium was evaluated [9]. The Euclidean distance of epinastine $\mathrm{HCl}$ to water was 300.63 in comparison to 376.70 for quinine $\mathrm{HCl}$ which indicated that epinastine $\mathrm{HCl}$ has similar bitterness to quinine $\mathrm{HCl}$. The human sensory test gave a bitterness score of 5.1 for pure epinastine $\mathrm{HCl}$ and scores of 3.5, 2.8 and 2.2 for epinastine $\mathrm{HCl}$ taste masked solutions containing different concentrations of acesulfame potassium $0.05,0.050$ and $0.150 \mathrm{mg} / \mathrm{ml}$ respectively [9]. The relationship between actual bitterness scores from human panel and Euclidean distance of taste masked epinastine $\mathrm{HCl}$ to placebo ( $\mathrm{A}$ to $\mathrm{P})$ showed a good correlation $\left(\mathrm{r}^{2}=0.9787\right)$. Also a good correlation was found between bitterness scores and Euclidean distance of taste masked epinastine $\mathrm{HCl}$ to pure drug ( $\mathrm{A}$ to $\mathrm{A})\left(\mathrm{r}^{2}=0.9891\right)$. PLS analysis indicated good correlation between predicted bitterness (electronic tongue and actual bitterness (human sensory test) for taste masked epinastine $\mathrm{HCl}$ formulation $\left(r^{2}=0.9996\right)[9]$.

In Maniruzzaman et al. [8], the taste of Citrizine $\mathrm{HCl}$ and Verapamil $\mathrm{HCl}$ was evaluated and correlated with human taste panel by using PLS. In human taste panel test (6 volunteers), pure drug/extrudates containing equivalent to $100 \mathrm{mg}$ drug were held in the mouth for $60 \mathrm{~s}$ and then spat out. Bitterness was recorded using a scale of $1=$ none, $2=$ threshold, $3=$ =moderate, $4=$ bitter to $5=$ strong bitterness [8]. A similar dose (100 mg drug) was used in electronic tongue analysis. A good correlation was found $\left(r^{2}>0.8\right)$ (predicted bitterness scores from electronic tongue versus bitterness scores from taste panel). However, data from the taste panel should be carefully considered as the number of panellists and variability on measurements was not disclosed [8].

In studies by Nakamura et al. [12], the taste of famotidine and amlodipine besylate orally disintegrating tablets (ODT) was assessed using the Astree electronic tongue and a human taste panel. In the human taste panel (31 volunteers), the taste of the tablet was evaluated after its disintegration in the oral cavity using a $100 \mathrm{~mm}$ VAS scale [12]. Volunteers perceived the ODT containing no flavouring or 
sweetening agent bitter (lowest mean score of 28.7 and 16.9 for famotidine and amlodipine respectively), while palatability improved with addition of flavouring/or sweetening agent [12]. In the electronic tongue analysis, the Euclidean distances (between ODT and placebo) were shorter for the ODT containing flavouring (317.2) or sweetening agent (243.3) or both (61.4) than the ODT without taste masking (392.7) [12]. Plotting clinical VAS scores versus Euclidean distances resulted in good correlation ( $\mathrm{r}^{2} 0.95$ and 0.93 for famotidine and amlodipine respectively). This correlation plot was then used to calculate predicted VAS score using electronic tongue data. PLS analysis was used to correlate between VAS scored predicted from electronic tongue and clinical VAS scores (human taste panel). According to PLS regression good correlation was obtained $\left(r^{2}=0.923\right.$ and 0.939 for famotidine and amlodipine ODTs) [12]. These studies confirmed that Astree electronic tongue could be used for taste evaluation of ODTs and Euclidean distances for correlation with human taste data [12]. Similar results were reported by Pimparade et al. [13]. Taste data of caffeine citrate ODT obtained from electronic tongue (Euclidean distance drug/placebo) was similar to human taste data (no correlation plot was constructed) [13].

All the studies mentioned above reported that taste data obtained using $\alpha$ Astree sensors showed good correlation with human taste panel data. However in most of these studies; the method followed for constructing bitterness prediction model in the electronic sensor was not fully described. Direct comparison of electronic tongue data (e.g. Euclidean distance) with human data might provide more robust correlation than bitterness prediction model.

\subsubsection{Insent electronic tongue}

Several studies showed that taste data evaluated using Insent electronic sensors correlated well with human taste panel test $[14,15]$. In these studies the aftertaste sensor output (CPA) was used as drug bitterness measure. The CPA values (AN0 sensor of SA501C) were successfully used in prediction of bitterness of amlodipine ODT [14]. In human taste panel test (6 volunteers), quinine $\mathrm{HCl}$ was used as standard for bitterness with concentrations of $0.01,0.03,0.10,0.3$ and $1 \mathrm{mM}$ corresponding to bitterness scores of $0,1,2,3$ and 4 respectively [14]. Amlodipine ODT bitterness was evaluated after the tablet was kept in the mouth for 10, 20 and $30 \mathrm{~s}$. The taste of dissolved drug after 10,20 and $30 \mathrm{~s}$ (50 mg in $100 \mathrm{ml}$ water) was assessed using electronic sensor and there was correlation with human taste panel $\left(r^{2}=0.54\right)$ [14] despite different conditions used $((100 \mathrm{ml}$ of water versus few $\mathrm{ml}$ of saliva). In another study CPA values (C00, SA402B) were successfully used for determination of bitterness of acidic non-steroidal anti-inflammatory drugs and were compared to human taste panel test [15]. In the human taste panel test (6 volunteers), quinine $\mathrm{HCl}$ was used as the standard for bitterness with concentrations of $0.01,0.03,0.10,0.3$ and $1 \mathrm{mM}$ corresponding to bitterness scores of $0,1,2,3$ and 4 respectively. The panel had to keep concentrations of $0.1,1$ and $10 \mathrm{mM}$ in the mouth for 10s. Similar concentrations were assessed using the electronic tongue. 
There was a good correlation using Pearson's test $(r=0.83)$ [15]. These results confirmed that CPA values could be used for the prediction of bitterness of drugs.

\subsubsection{Astree and Insent electronic tongues}

Maniruzzaman et al. assessed the taste of propanolol using two taste sensing systems (Astree and TS5000Z) and human taste panel [7]. In the human taste panel test, pure drug/extrudates containing the equivalent of $100 \mathrm{mg}$ of API were held in the mouth for $60 \mathrm{~s}$ and then spat out (6 volunteers). Bitterness was recorded (from $1=$ none, $2=$ threshold, $3=$ moderate, $4=$ bitter to $5=$ strong bitterness). Volunteers perceived pure drug bitter (score 5), while propanolol polymer extrudates were nonbitter (Drug-Eudragit $\AA^{\circ}$ L100 or L100-55 scored 1 at drug/polymer ratio of 10:90\% $\mathrm{w} / \mathrm{w}$ ). Analysis of these extrudates at a similar drug dose $(100 \mathrm{mg}$ dissolved in $25 \mathrm{ml}$ deionised water for 60s) using the Astree electronic tongue showed better taste masking in case of Eudragit $\AA$ L100 compared to Eudragit ${ }^{\circledR}$ L100-55 [7]. This difference was explained by the use of deionised water which resulted in variation of dissolution rates of these extrudates made with different $\mathrm{pH}$ depend polymers. This resulted in faster release of drug from Eudragit $\AA^{\circledR}$ L100-55 [7]. PLS model was used to correlate Astree electronic tongue data with human taste panel data which revealed a good correlation for both drug-Eudragit ${ }^{\circledR} L 100 \quad\left(R^{2}=0.9892\right)$ and Eudragit $\circledast$ L100-55 $\left(R^{2}=0.9959\right)$ extrudates [7]. The taste of extrudates in artificial saliva at $0.5,1,10$ and 30 min was assessed using BT0 sensor with the Insent electronic tongue in comparison to pure propanolol $(0.09 \mathrm{mg} / \mathrm{ml})$ [7]. Insent showed better taste masking when Eudragit $\Theta$ L100 was used compared to Eudragit $\Theta$ L10055, matching the Astree findings aforementioned. CPA values were plotted against human panel bitterness scores and showed a good correlation $\left(R^{2}=0.94\right)$ [7]. The drug extrudates concentration used in the Insent was lower than concentration used in both the human taste panel and the Astree electronic tongue tests because BT0 showed response to a lower concentration range of the pure drug (0.009-0.296 $\mathrm{mg} / \mathrm{ml}$ ) [7]. Therefore, direct comparison of Insent electronic tongue data with human taste panel test and Astree electronic tongue was not possible. The PLS model used in correlation of the Astree electronic tongue data and the human taste panel data was not fully described. Furthermore, the number of panellists and the variability of measurement were not reported.

To sum up, it is very important to mention clearly the method of constructing the bitterness prediction model in order to obtain reliable electronic sensors data. To achieve good bitterness prediction, human taste data either supplied by the manufacturer or conducted in the experiment should be used to this model. Alternatively, data from sensor response (relative value $\mathrm{mV}$ or CPA, Euclidean distances) can be correlated directly with human taste panel data. Good correlation between taste data obtained using electronic sensor (Insent and Astree) and human taste data can be achieved when same solutions of APIs were analysed simultaneous by these methods. However, most of the studies discussed here have used electronic sensors to evaluate specific bitter compounds or set of bitter 
compounds (similar chemical properties) that gave good correlation with human data which might not be achieved if other bitter compounds (different chemical nature) are evaluated. Electronic sensors can quantify bitterness of compounds in question and the correlation might not be transferable to other bitter compounds with different chemical nature. The number of panellists in some of the studies discussed here is low (6 sometimes) whereas it is recommended to have 10-15 panellists (ISO 13299). Moreover, as the scale is not often enough discriminant, this might affect the robustness of the correlation. 
Table 1. Examples of taste evaluation of pure APIs, commercial and preclinical taste masked formulations using electronic taste sensor. (NS=not stated and ODT=orodispersable tablet). PCA is principle component analysis.

\begin{tabular}{|c|c|c|c|c|c|c|}
\hline Product or Pure API & $\begin{array}{l}\text { Dosage } \\
\text { Form }\end{array}$ & $\begin{array}{l}\text { Sensor } \\
\text { type }\end{array}$ & $\begin{array}{l}\text { Drug dose } \\
(\mathrm{mg} / \mathrm{ml})\end{array}$ & Sample preparation & Results & REF \\
\hline H1-antihistaminics & Pure drugs & Astree & 0.03 & $\begin{array}{l}\text { Dissolved in purified water. } \\
\mathrm{T}=\mathrm{NS}\end{array}$ & $\begin{array}{l}\text { Relative sensor output (AB } \\
\text { and JE) in } P C A \text { analysis (no } \\
\text { specific reason) }\end{array}$ & [9] \\
\hline Berberine HCL & $\begin{array}{l}\text { Chinese } \\
\text { medicine }\end{array}$ & Astree & $\begin{array}{l}0.93,4.66 \\
9.30 \text { and } \\
18.63\end{array}$ & $\begin{array}{l}\text { Dissolved in purified water. } \\
\mathrm{T}=\mathrm{NS}\end{array}$ & $\begin{array}{l}\text { Relative sensor output (all } \\
\text { sensors) }\end{array}$ & [10] \\
\hline Sildenafil citrate & $\begin{array}{l}\text { Pure drug } \\
\text { Microcapsules } \\
\text { (Eudragit } \AA \text { ) }\end{array}$ & Astree & 0.1 & $\begin{array}{l}\text { Amount of drug equivalent to } 10 \mathrm{mg} \\
\text { sildenafil free base dissolved in } 100 \mathrm{ml} \\
\text { artificial saliva buffer solution ( } \mathrm{pH} 6.2) \\
\text { Stirring for } 180 \mathrm{~s} \text { and then filtration ( } 0.45 \\
\text { um nylon membrane) at room } \\
\text { temperature. }\end{array}$ & $\begin{array}{l}\text { Relative sensor output for ZZ, } \\
\text { BB and CA were used in PCA } \\
\text { analysis (other sensor were } \\
\text { excluded because of their low } \\
\text { discriminating power). }\end{array}$ & {$[16]$} \\
\hline $\begin{array}{l}\text { Citrizine } \mathrm{HCl}, \\
\text { Verapamil HCL }\end{array}$ & $\begin{array}{l}\text { Pure drugs } \\
\text { Melt extruded } \\
\text { with Eudragit@ }\end{array}$ & Astree & 14 & $\begin{array}{l}\text { Dissolved in deionised water }(25 \mathrm{ml}) \text {. } \\
\text { Stirring for } 60 \text { seconds then filtration } \\
\text { using filter paper }(2.5 \mu \mathrm{m} \text { pore size }) \\
\text { through Buchner funnel for } 60 \mathrm{~s} \text {. } \\
\mathrm{T}=\mathrm{NS}\end{array}$ & $\begin{array}{l}\text { All sensors relative outputs } \\
\text { were used in PCA analysis. }\end{array}$ & [8] \\
\hline $\begin{array}{c}\text { Famotidine } \\
\text { Amlodipine Besylate }\end{array}$ & $\begin{array}{l}\text { ODT } \\
\text { (spray ethyl } \\
\text { cellulose } \\
\text { coated } \\
\text { granules) }\end{array}$ & Astree & $\begin{array}{c}2 \\
0.5\end{array}$ & $\begin{array}{l}\text { ODT dissolved in distilled water }(10 \mathrm{ml}) \\
\text { with stirring for } 30 \text { s then filtration through } \\
\text { funnel fitted filter paper and further } \\
\text { filtration through } 0.45 \mu \mathrm{m} \text { Millipore filter } \\
\text { Finally dilution } 10 \text { folds in distilled water. } \\
\text { T=NS }\end{array}$ & $\begin{array}{l}\text { All sensors relative outputs } \\
\text { were used in PCA analysis. }\end{array}$ & [12] \\
\hline Caffeine citrate & $\begin{array}{l}\text { ODT (ethyl } \\
\text { cellulose melt } \\
\text { extrudates) }\end{array}$ & Astree & 5 & $\begin{array}{l}\text { Sample }(0.05 \mathrm{~g}) \text { dispersed in phosphate } \\
\text { buffer saline }(\mathrm{pH}=6.8,50 \mathrm{ml}) \text {. Shaking } \\
\text { gently for } 30 \mathrm{~s} \text { and then filtration (syringe } \\
\text { nylon membrane } 0.45 \mu \mathrm{m}) . \mathrm{T}=\mathrm{NS}\end{array}$ & $\begin{array}{l}\text { All sensors relative outputs } \\
\text { were used in PCA analysis. }\end{array}$ & [13] \\
\hline
\end{tabular}




\begin{tabular}{|c|c|c|c|c|c|c|}
\hline Product or Pure API & $\begin{array}{c}\text { Dosage } \\
\text { Form }\end{array}$ & $\begin{array}{c}\text { Sensor } \\
\text { type }\end{array}$ & $\begin{array}{c}\text { Drug dose } \\
(\mathrm{mg} / \mathrm{ml})\end{array}$ & Sample preparation & Results & REF \\
\hline $\begin{array}{l}\text { Amlodipine (Amlodine® OD) } \\
\text { Other nine generic OD products. }\end{array}$ & $\begin{array}{l}\text { Orally } \\
\text { disintegrating } \\
\text { tablets }\end{array}$ & SA501C & 50 & $\begin{array}{l}\text { Ten tablets in a stainless-steel basket } \\
\text { placed in } 100 \mathrm{ml} \text { of purified water }(25 \mathrm{rpm} \\
\left.\text { at } 37^{\circ} \mathrm{C}\right) . \text { After } 10,20 \text { and } 30 \mathrm{~s} \text {, the } \\
\text { solutions were filtered. }\end{array}$ & CPA (sensor AN0). & {$[14]$} \\
\hline Quinine $\mathrm{HCl}$ & Pure drug & & & $\mathrm{T}=37^{\circ} \mathrm{C}$ & & \\
\hline Cetirizine $\mathrm{HCl}$ & $\begin{array}{l}\text { Lyophilisates } \\
\text { cyclodextrin }\end{array}$ & TS-5000Z & 2 & $\begin{array}{l}\text { Samples dissolved in } 100 \mathrm{ml} \text { of water (at } \\
\text { dose equivalent to } 10 \mathrm{mg} / 5 \mathrm{ml} \text { drug). }\end{array}$ & $\begin{array}{l}\text { All sensors relative outputs } \\
\text { were used in PCA analysis. }\end{array}$ & {$[11]$} \\
\hline $\begin{array}{l}\text { Non-steriodal anti-inflammatory } \\
\text { drugs (e.g. diclofenac sodium) }\end{array}$ & Pure drugs & SA402B & $\begin{array}{l}0.03,0.3 \\
\text { and } 3\end{array}$ & NS & $\begin{array}{l}\text { Relative sensor (CA0) output } \\
\text { and CPA (CO0). }\end{array}$ & {$[15]$} \\
\hline Propanolol HCl & $\begin{array}{l}\text { Melt extrudes } \\
\text { with Eudragit } \AA \\
\text { Pure drug }\end{array}$ & $\begin{array}{l}\text { 2.TS5000 } \\
Z\end{array}$ & 0.5 & $\begin{array}{l}\text { 1. Drug extrudates dissolved in } \\
\text { deionised water }(25 \mathrm{ml}) \text { for } 60 \mathrm{~s} \text { then } \\
\text { filtrated through a Buchner with a } \\
2.5 \mu \mathrm{m} \text { filter. } \\
\text { 2. Extrudates dissolved in } \mathrm{KCl}(10 \mathrm{mM} \text {, } \\
50 \mathrm{ml}) \text { then filtered through a } \\
\text { Buchner with } 2.5 \mu \mathrm{m} \text { membrane. } \\
\mathrm{T}=\mathrm{NS}\end{array}$ & $\begin{array}{l}\text { 1. All sensors relative outputs } \\
\text { were used in PCA analysis. }\end{array}$ & [7] \\
\hline
\end{tabular}




\section{In vitro drug release and dissolution}

The measurement of the amount of drug released/dissolved in simulated oral cavity conditions can give an idea about the taste of the drug. Only dissolved drug molecules would interact with the taste receptors in the human taste buds. Analytical methodologies used for assessing drug release and dissolution have been thoroughly described to screen taste masked oral formulations in other reviews [17, 18]. Parameters such as volume $(1-2 \mathrm{ml})$, temperature $\left(35-36^{\circ} \mathrm{C}\right), \mathrm{pH}(5.7-7.5)$ and osmolarity of saliva (50-100 mosmole/kg) as well as exerted sensor force $(0.135 \mathrm{~N})$ (especially in case of solid dosage form such as orodispersible tablets) should be taken into consideration when mimicking oral cavity conditions [17, 18], which is critical and challenging as it is a dynamic environment (fresh saliva is produced continuously, the dosage forms disintegrate, the tastant is washed away etc). Information about sampling method, sample preparation, such as filtration and analytical method (inline or offline), is very important as there might be ongoing dissolution of the drug which could affect the results [17, 18]. Examples of release/dissolution studies for pure drug and taste masked formulation are shown in Table 2. The most common bias in these studies are: (1) the use of larger dissolution medium far exceeding normal human saliva volume, (2) uncontrolled $\mathrm{pH}$ for e.g. use of water as dissolution medium and, (3) filtration of sample and/or inline analytical method are not used (Table 2).

\subsection{Correlation of release/dissolution data with human taste data}

The correlation of release/dissolution data with human taste panel test can be done by; (1) comparison of concentration of released/dissolved drug with human bitterness threshold and/or (2) conducting simultaneous drug release and human taste studies using similar drug concentrations and time points. The conditions used in these release/dissolution studies are described in Table 2.

Kharb et al. [19] looked at the human bitterness threshold of ondansteron determined by assessing its bitterness at 22, 40,60,100, 200, 400 and $600 \mu \mathrm{g} / \mathrm{ml}$ using the swirl and spit method (10 $\mathrm{ml}$ for $30 \mathrm{~s})$. A bitterness score of $0=$ pleasant, $1=$ tasteless, $2=$ slightly bitter, $3=$ moderately bitter to $4=$ =strongly bitter was used. All 12 volunteers reported $22 \mu \mathrm{g} / \mathrm{ml}$ as tasteless but $40 \mu \mathrm{g} / \mathrm{ml}$ bitter which was set as the threshold. A drug concentration-bitterness score curve was constructed, and a polynomial equation for bitterness estimation was established $\left(y=0.6206 x^{2}-0.2011 x-\right.$ 0.7796 , where $x$ is log drug concentration and $y$ is bitterness score). This equation was used to predict bitterness score of ondansteron and correlate the amount of ondanstron released after 5 min with human taste data. The amount of drug released from pure drug and the marketed tablet (Vomikind-MD 4) was 56.21 and $48.73 \%$ respectively which was higher than bitterness threshold. The predicted bitterness scores were similar to estimated scores by human taste panel $\left(R^{2}\right.$ values 0.990 0.998) from linear regression and residual plot [19]. Furthermore, low value of percentage bias was observed. The polynomial model was considered as valid [19]. 
Lahoti et al. [20] checked the amount of Ondansetron $\mathrm{HCl}$ released from resinate in phosphate buffer saline and compared to human bitterness threshold. Their bitterness threshold was determined in humans using concentrations from 10 to 50 $\mu \mathrm{g} / \mathrm{ml}$ in phosphate buffer ( $\mathrm{pH}$ 6.7) by swirling $10 \mathrm{ml}$ in mouth for $30 \mathrm{~s}$ before spitting out [20]. Bitterness threshold was found to be $40 \mu \mathrm{g} / \mathrm{ml}$. Ondansetron $\mathrm{HCl}$ released even after 120s was less than $40 \mu \mathrm{g} / \mathrm{ml}$ therefore ondasteron resinates were non bitter [20].These results indicated the feasibility of predicating the taste sensation by comparing the amount of released/dissolved drug and with human bitterness threshold.

Stange et al. [21] determined the human bitterness threshold of naproxen sodium using concentration range from 0.01 to $10 \mathrm{mg} / \mathrm{ml}$. There was high variability between individuals ( 7 healthy volunteers only) with threshold ranging from 0.063 $5.999 \mathrm{mg} / \mathrm{ml}$ with the majority in the range of $0.2-0.7 \mathrm{mg} / \mathrm{ml}$ [21]. The average value of all the measured concentrations was found to be $1.124 \mathrm{mg} / \mathrm{ml}$ for naproxen sodium and was set as the bitterness threshold [21]. The amount of naproxen sodium released from Eudragit ${ }^{\circledR}$ E coated granules after 5 min in $25 \mathrm{ml}$ of PBS was below this threshold. The taste of naproxen sodium granules was also assessed in healthy volunteers: the granules were held in the mouth for 5 min before being spat out and were not perceived as bitter by most of the volunteers $(9 / 12)$ which showed similar results despite in vitro/vivo different conditions.

Tan et al. [22] established the bitterness threshold of pyridostigmine bromide in 18 healthy volunteers by crushing tablets $(1,2,3,4$ and $5 \mathrm{mg})$ and after holding for $30 \mathrm{~s}$ in the mouth It was found to be $4 \mathrm{mg}$. The amounts of pyridostigmine bromide released from pure drug powder, solid dispersion with Eudragit $\circledast$ powder and ODT (20 mg drug) in $900 \mathrm{ml}$ simulated saliva fluid (SSF) after 30 s were $98.72 \pm 1.59,7.89 \pm 1.12$ and $8.56 \pm 0.42 \%$ respectively which were less than human bitterness threshold in the case of solid dispersion and ODTs. However, as the experimental conditions of the dissolution were very different than the oral cavity, the correlation the authors established is debatable [22]. Hu et al. [23] established that the amount of $50 \mathrm{mg}$ Berberine $\mathrm{HCl}$ Eudragit ${ }^{\circledR}$ E100 microcapsules (ODT) dissolved in $1000 \mathrm{ml}$ of water after $20 \mathrm{~min}$ was only $0.56 \%$ (indicating successful taste masking), whereas the panel perceived microcapsules ODT (25 mg) to be non bitter after 30s. Although dissolution data and human panel data were consistent, direct comparison between in vitro dissolution test and human taste panel cannot be made as a different dose was used in each test [23].

Several studies used both electronic tongue and drug release/dissolution as in vitro tools for taste evaluation of drugs [14, 16, 24]. In study by Yi et al. [16], 100\% of sildenafil citrate $(10 \mathrm{mg})$ was released in distilled water $(900 \mathrm{ml})$ within 5 mins [16]. Human volunteers found sildenafil citrate pure powder bitter [10 $\mathrm{mg}$, score of $3.3 \pm 0.52$, bitterness scale of $0=$ no taste, $1=$ threshold, $2=$ slightly bitter, $3=$ bitter, to $4=$ remarkably bitter after holding it in the mouth for 30 s. The Authors mentioned that similar results were obtained when the taste of sildenafil citrate $(10 \mathrm{mg} / 100 \mathrm{ml})$ was assessed using an electronic tongue (Astree II) [16]. However, as the 
concentrations of sildenafil citrate assessed using these three methods were different, direct correlations made might not be reliable [16]. Uchida et al. [14] measured the bitterness of commercial amlodipine orally disintegrating using brief dissolution test, Insent electronic tongue (SA501C) and a human panel. There was no correlation between the amount of amlodipine dissolved after 10,20 and 30s and the bitterness intensity perceived by the human panel. Analysis of the same dissolution media by the taste sensor gave results similar to the human taste panel test. The lack of agreement between the dissolution test and the human taste panel data was explained by the presence of taste masking agents in the ODT. These taste masking agents were not taken into account in the dissolution test but only the amlodipine concentration [14]. Similar findings were described in studies by shah et al. [25], where the drug release studies showed a similar profile for both the ODT and the ODF of Chorpheniramine Maleate with approximately $40 \%$ drug release within 5 mins [25]. Human taste panel showed complete masking for ODT microparticles and moderate to slight bitterness for ODF after holding in mouth for 45s. The ODT was better than the ODF, although there was no significant difference in the release profile between the two formulations. This difference was explained by the presence of mannitol (sweet taste) as a filler in the ODT [25]. These studies confirmed that dissolution/release studies cannot detect the effect of the excipients on the taste of the drug and that release/dissolution studies cannot be used alone to determine the taste of an API in a taste masked formulation containing taste masking agents such as sweetener. 
Table 2. Examples of in vitro drug release/or dissolution of pure API and formulations used for taste assessment. NS=non stated.

\begin{tabular}{|c|c|c|c|c|c|c|c|}
\hline Product or Pure API & $\begin{array}{l}\text { Drug dose } \\
\text { (mg) }\end{array}$ & $\begin{array}{c}\text { Dissolution medium } \\
\text { type, } \mathrm{T}, \mathrm{pH}\end{array}$ & $\begin{array}{c}\text { Dissolution } \\
\text { method }\end{array}$ & $\begin{array}{l}\text { Mixing } \\
\text { method }\end{array}$ & Sampling method & $\begin{array}{l}\text { Analytical } \\
\text { method }\end{array}$ & Ref \\
\hline $\begin{array}{l}\text { Ondansetron } \mathrm{HCl} \\
\text { (pure drug and } \\
\text { marketed tablet) }\end{array}$ & 8 & $\begin{array}{l}\text { Phosphate buffer }(25 \mathrm{ml}) \\
\mathrm{T}=\mathrm{NS} \\
\mathrm{pH}=6.8\end{array}$ & Volumetric flask & Stirring & $\begin{array}{l}\text { Aliquot withdrawn } \\
\text { after } 5 \text { min. }\end{array}$ & $\begin{array}{l}\text { UV } \\
\text { spectrometer }\end{array}$ & [19] \\
\hline $\begin{array}{l}\text { Pyridostigmine } \\
\text { bromide } \\
\text { (pure drug, solid } \\
\text { dispersion Eudragit® } \\
\text {, ODT) }\end{array}$ & 20 & $\begin{array}{l}\text { Simulated salivary fluid } \\
\text { (SSF) }(900 \mathrm{ml}) \\
T=37 \pm 0.5 \quad \mathrm{pH}=6.2\end{array}$ & $\begin{array}{l}\text { Paddle method- } \\
\text { China } \\
\text { pharmacopeia } \\
2010 .\end{array}$ & $\begin{array}{l}\text { Continuous } \\
\text { Stirring at } \\
100 \mathrm{rpm} .\end{array}$ & $\begin{array}{l}\text { Aliquot withdrawn } \\
\text { at time intervals } \\
\text { 30s-upto } 45 \text { mins. }\end{array}$ & HPLC & [22] \\
\hline $\begin{array}{l}\text { Sildenafil citrate } \\
\text { (pure drug) }\end{array}$ & 10 & $\begin{array}{l}\text { Distilled water } \\
(900 \mathrm{ml}) \\
\mathrm{T}=37 \pm 0.5 \mathrm{pH}=\mathrm{NS}\end{array}$ & $\begin{array}{c}\text { USP dissolution } \\
\text { test apparatus type } \\
\text { II }\end{array}$ & $\begin{array}{l}\text { Paddle } \\
\text { rotating at } 50 \\
\text { rpm. }\end{array}$ & $\begin{array}{l}\text { Aliquot withdrawn } \\
\text { at time intervals } 5 \text { - } \\
120 \text { min }\end{array}$ & HPLC & [16] \\
\hline $\begin{array}{l}\text { Ondansetron } \mathrm{HCl} \\
\text { resinate (Indion } 244 \\
\text { resin) }\end{array}$ & 4 & $\begin{array}{l}\text { Phosphate buffer }(10 \mathrm{ml}) \\
\mathrm{T}=\mathrm{NS} \\
\mathrm{pH}=6.7\end{array}$ & Volumetric flask & $\begin{array}{l}\text { Stirring at } 50 \\
\text { rpm }\end{array}$ & $\begin{array}{l}\text { Samples withdrawn } \\
\text { and filtered after } \\
10,30,60 \text { and } 120 \\
\text { s. }\end{array}$ & $\begin{array}{l}\text { UV } \\
\text { spectrometer }\end{array}$ & [20] \\
\hline $\begin{array}{l}\text { Naproxen sodium } \\
\text { Eudragit } \AA \text { E coated } \\
\text { granules. }\end{array}$ & 200 & $\begin{array}{l}\text { Phosphate buffer }(25 \mathrm{ml}) \\
\mathrm{T}=\mathrm{NS} \\
\mathrm{pH}=6.8\end{array}$ & Volumetric flask & $\begin{array}{l}\text { shaken for } 5 \\
\text { mins }\end{array}$ & $\begin{array}{l}\text { Samples collected } \\
\text { and filtered }(0.2 \\
\mu \mathrm{m}) . \text { after } 5 \mathrm{~min}\end{array}$ & $\begin{array}{l}\text { UV } \\
\text { spectrometer }\end{array}$ & [21] \\
\hline $\begin{array}{l}\text { Amlodipine } \\
\text { (Amlodine® ODT). } \\
\text { Other nine generic } \\
\text { OD products. }\end{array}$ & 50 & $\begin{array}{l}\text { Purified water }(100 \mathrm{ml}) \\
\mathrm{T}=37^{\circ} \mathrm{C} \\
\mathrm{pH}=\mathrm{NS}\end{array}$ & $\begin{array}{l}\text { Brief conventional } \\
\text { dissolution test } \\
\text { (using Basket } \\
\text { apparatus) }\end{array}$ & $\begin{array}{l}\text { Shaking at } \\
25 \mathrm{rpm}\end{array}$ & $\begin{array}{l}\text { Samples collected } \\
\text { and filtered after } \\
10,20 \text { and } 30 \text { s. }\end{array}$ & HPLC & [14] \\
\hline $\begin{array}{l}\text { Chorpheniramine } \\
\text { Maleate ODT and } \\
\text { ODF of spray dried } \\
\text { drug-Eudragit@ PEO }\end{array}$ & 1.3 & $\begin{array}{l}\text { SSF }(300 \mathrm{ml}) \\
\mathrm{T}=37^{\circ} \mathrm{C} \\
\mathrm{pH}=6.8\end{array}$ & $\begin{array}{l}\text { USP basket } \\
\text { apparatus }\end{array}$ & $\begin{array}{l}\text { Rotation at } \\
50 \text { rpm }\end{array}$ & $\begin{array}{l}\text { Inline concentration } \\
\text { monitoring }\end{array}$ & $\begin{array}{l}\text { Inline } \\
\text { ultraviolet } \\
\text { detector. }\end{array}$ & [25] \\
\hline $\begin{array}{l}\text { Berberine } \mathrm{HCl} \\
\text { Eudragit }{ }^{\circledR} \mathrm{E} 100 \\
\text { microcapsules (ODT) }\end{array}$ & 50 & $\begin{array}{l}\text { Purified water }(1000 \mathrm{ml}) \\
\mathrm{T}=37 \pm 0.5^{\circ} \mathrm{C} \\
\mathrm{pH}=6.3\end{array}$ & $\begin{array}{l}\text { Microcapsules were } \\
\text { placed in SSF }\end{array}$ & NS & $\begin{array}{l}\text { Aliquots withdrawn } \\
\text { at various time } \\
\text { intervals up to } 20 \\
\text { min }\end{array}$ & $\begin{array}{l}\text { UV } \\
\text { spectrometer }\end{array}$ & [23] \\
\hline
\end{tabular}




\section{(B) Animal models for taste evaluation}

Some animal models are designed to measure the taste quality of a compound defined as the sense by which the qualities and flavour of a substance are distinguished by the taste buds (e.g. bitter, salty, sweet, umami and sour): these models are classified as "taste discrimination experiments". Alternatively studies of "taste-guided" behaviour can assess the palatability of tastants defined by the overall appreciation of a substance by organoleptic properties such as vision, smell, taste, aftertaste and mouth feel (e.g. good/bad taste and aversive). Animal models such as the conditioned taste aversion (CTA), the operant taste discrimination, the high throughput taste assessment model using 96-well plates, two-bottle taste preference test and the brief-access taste aversion (BATA) model have shown promising results for identifying bitter-tasting compounds [26] and examples are shown in Table 3.

In the conditioned taste aversion paradigm, the rats are presented to a reference taste (conditioned stimuli), which becomes associated with an aversive stimulus such as peritoneal injections of lithium chloride ( $\mathrm{LiCl}$ ). As a consequence, when the rat is exposed to novel compounds with a similar taste, they will avoid it as a function of their similarity to the conditioned stimuli [27]. This model can assess the taste quality of a drug, not its palatability and has the disadvantage of requiring an aversive conditioning and a high number of animals to investigate the response similarity among a large number of stimuli [28].

The operant taste discrimination model is an animal model in which rats are trained to perform a specific behavioural task such as pressing a lever after having tasted a certain compound and an alternative task after sampling another tastant that can be distinguished from the first one [29]. When a novel tastant is presented to the animal, it will perform the task learnt depending on the degree of similarity of the new compound to the two compounds learnt. In this procedure, only the taste quality of the drug can be evaluated. Moreover, long training is needed and only pairwise comparisons can be tested on each trial [28].

In the high throughput taste assessment model, rats are trained to sample different tastants in a standard 96-well plate, and then perform an operant discrimination task: pressing levers to deliver food pellets [26]. In this method, taste quality is assessed by the taste discrimination component whereas palatability is evaluated by the licks recorded from the 96-well plate. This animal model has the advantage of requiring few animals (cohorts of 3 to 4 rats), assessing both taste quality and palatability and can screen a high number of samples within a single session. However, the entire training process is very long (up to 7 weeks) and a single concentration of the reference taste stimuli is used for the training which can lead to the risk of inadvertently establishing a discrimination based on the stimulus intensity rather than the taste quality [26].

In the two-bottle taste preference experiment, animals have free access in their cage to two different bottles, one containing a taste solution and the other 
containing water or a different taste solution. This test is usually 48 hours in duration to assess a single concentration. After 24 hours, the relative positions of the two bottles are counterbalanced because rodents can have pronounced side preferences. The volume missing from each bottle is measured and a preference ratio of tastant to water is then calculated [30]. This procedure is the simplest animal model available to assess the palatability of solutions. However, the interpretation of the data obtained should be done cautiously. Indeed, intakes and preferences reflect post-ingestive effects such as toxicity or satiety as well as chemosensory ones. Moreover, additional physiological effects that result following ingestion of tastants ad libitum over a large period of time could influence intake of the solutions. Last but not least, this method has the disadvantage of being very long. Even if a daily measurement can be made very quickly, several weeks or months are needed to test different concentrations of the same compound [31].

In the brief-access taste aversion (BATA) model, rodents, most often mice or rats, are mildly water-deprived for a period of 16 to 24 hours in order to motivate them to drink. The rodents are then put into an apparatus called a "lickometer" which records the number of licks that the rodents make to different concentrations of the compound under test samples presented in several sipper tubes. Animals only have a very short period of time (between 5 and 10 seconds) to sample a solution. Typically, a high number of licks indicate a pleasant taste whereas when licks are nearly completely suppressed it indicates an aversive taste. With this procedure, a full aversion-concentration curve of lick rate can be obtained over a short period of time, generally in 30 minutes. This procedure enables assessment of the palatability of drugs but not its taste quality. As subjects are water-deprived, the baseline for lick rates is relatively high making assessment of appetitive solutions difficult [26]. This animal model can assess several concentrations of a compound in a single session with few animals, it reflects the taste processing independent of other controls of appetitive behaviour, and because immediate responses are measured the intake of each sample is limited and post-ingestive factors are reduced or avoided [32].

\subsection{Correlation between animal models and human taste evaluation of medicines}

A comparison between rodent and human taste data has been done in a few studies. Devantier et al. [33] found that the relative potencies of four drugs (quinine, ciprofloxacin, clarithromycin, and nystatin) assessed in the mice brief-access taste aversion assay matched the taste intensities evaluated by a trained human taste panel. Moreover, the absolute potencies of the drugs in humans were within one-half log unit of molar concentration derived from the mouse BATA and did not differ statistically [33]. They found that mice were more sensitive than humans to the aversive taste of quinine and clarithromycin and less sensitive to the aversiveness of ciprofloxacin.

Rudnitskaya et al. [34] compared taste data obtained for eight drugs (azelastine hydrochloride, caffeine, chlorhexidine digluconate, potassium nitrate, 
naratriptan hydrochloride, paracetamol, quinine hydrochloride and sumatriptan succinate) with the rat BATA model and a trained human taste panel. The rat data showed exactly the same rank order of bitterness prediction as the human panel with a consistent offset of approximately half-log unit of molar concentration, with rats always rating the bitterness lower than humans [34]. They explained this offset by the fact that rats were encouraged to drink whilst the human panel was not [34]. Analysing deeper their methodology for the comparison of the rat BATA data and the human taste data, it was noticed that the concentrations tested were not necessarily the same for both panels and that for some compounds, e.g. quinine hydrochloride, the concentrations chosen in both panels were not even overlapping. Moreover, for some of the drugs they tested, the range of concentrations chosen was lower for the human panels than for the rat panels. Therefore, this can be one of the reasons why they always found that rats were less sensitive to the bitterness than humans.

Noorjahan et al. [35] assessed the taste of an iron EDTA complex dissolved in water as well as formulated in chewable and orodispersible tablets with a human taste panel and a rat BATA model. They found that the correlation coefficient between mean responses of rats and humans was above 0.5 and concluded of a good correlation. However, the methodology they used for the taste assessment with rats was different from the BATA procedure usually used as well as the data compared to previous published studies [35]. Rats were water-deprived for 24 hours and were then presented to a bottle containing water for $5 \mathrm{~min}$; the licking activity was taken as standard. After similar water-deprivation duration, rats were randomly presented to three different concentrations of the drug under assessment. The number of licks done in five minutes was counted and a percentage of licking frequency compared to water was calculated.

\subsection{Other in vivo models}

Other animal models such fish and drosophila flies have been recently used in taste screening of pure drugs. Fish and drosophila flies have taste receptor similar to mammals [36, 37]. The preferences of taste in fish have been performed by the observation and scoring of food sorting and consumption. Quantitative methods using fluorescent dye mixed with food have been used in Medaka fish larvae [38]. The intensity of ingested dye is measured using fluorescence microscope to determine preference scoring. This method can also be used in adult fish [38]. In study by Boyer et al. [39], fluorescently labelled food containing either amino acid or denatonium was given to adult zebra fishes [39]. The fluorescence of the remaining food (unconsumed) was measured to determine taste preference and was lower for denatonium spiked food. Similar results was observed in both zebra and Medaka fish [39].

Several studies proved that Drosophila melnogaster can distinguish between different basic taste qualities (sweet, bitter and salty) [40]. The taste can be assessed in drosophila flies using: (1) electrophysiological recording of nerve 
electrical activity elicited as response to certain tastant [41, 42], (2) behavioural feeding assays (capillary or petri dish feeding and two choice assay) where flies are starved for 22-24 $\mathrm{h}$ followed by feeding with a tastant solution [42-48], (3) survival assay [42] and, (4) Proboscis Extension Reflex (PER) where the extension of the proboscis is measured after applying the tastant to the forelegs [49].

Electrophysiological recording in drosophila flies involves several technical problems such as: (1) lack of signal due to unresponsive nerve, (2) presence of air bubbles in the recording electrode affecting the signal, (3) signal received higher or lower than amplifier measuring range, (4) death of flies during the preparation and, (5) presence of noise that does not represent signal from tastant. Furthermore, insoluble drugs cannot be assessed and there is a low throughput [41].

In the two choice assays, Drosophila larva flies are placed in agarose Petri dish. This Petri dish is half filled with tastant solution (e.g. quinine) and the other half contains pure agarose $[42,47]$. Flies are left to move free for $5 \mathrm{~min}$, and then the flies at each side are counted. The quinine side was avoided by the flies even at low concentration $(1 \mathrm{mM})$. The avoidance was found to be concentration dependant manner [42]. In the feeding assay, flies are left to feed on a Petri dish containing agarose solution (1\%) and tastant (e.g. quinine) for 30 mins. After this period the food intake is quantified [42, 48]. Feeding on quinine-agarose mixture was decreased compared to pure agarose at quinine concentration higher than $3 \mathrm{mM}$. In the survival assay; flies are placed in vials containing agarose solution (1\%) and tastant at $25^{\circ} \mathrm{C}$ [42]. The number of flies is counted each day for 7 consecutive days [42]. Survival of flies decreased in vials containing quinine, there was more reduction at $6 \mathrm{mM}$ when compared to $3 \mathrm{mM}$ quinine [42]. These behavioural assays using drosophila flies and fish might be promising tools for aversive taste screening of APIs. However no correlation has been made with human data in these studies. 
Table 3. Examples of taste assessment of APIs/formulation using animal models. NS=Not stated.

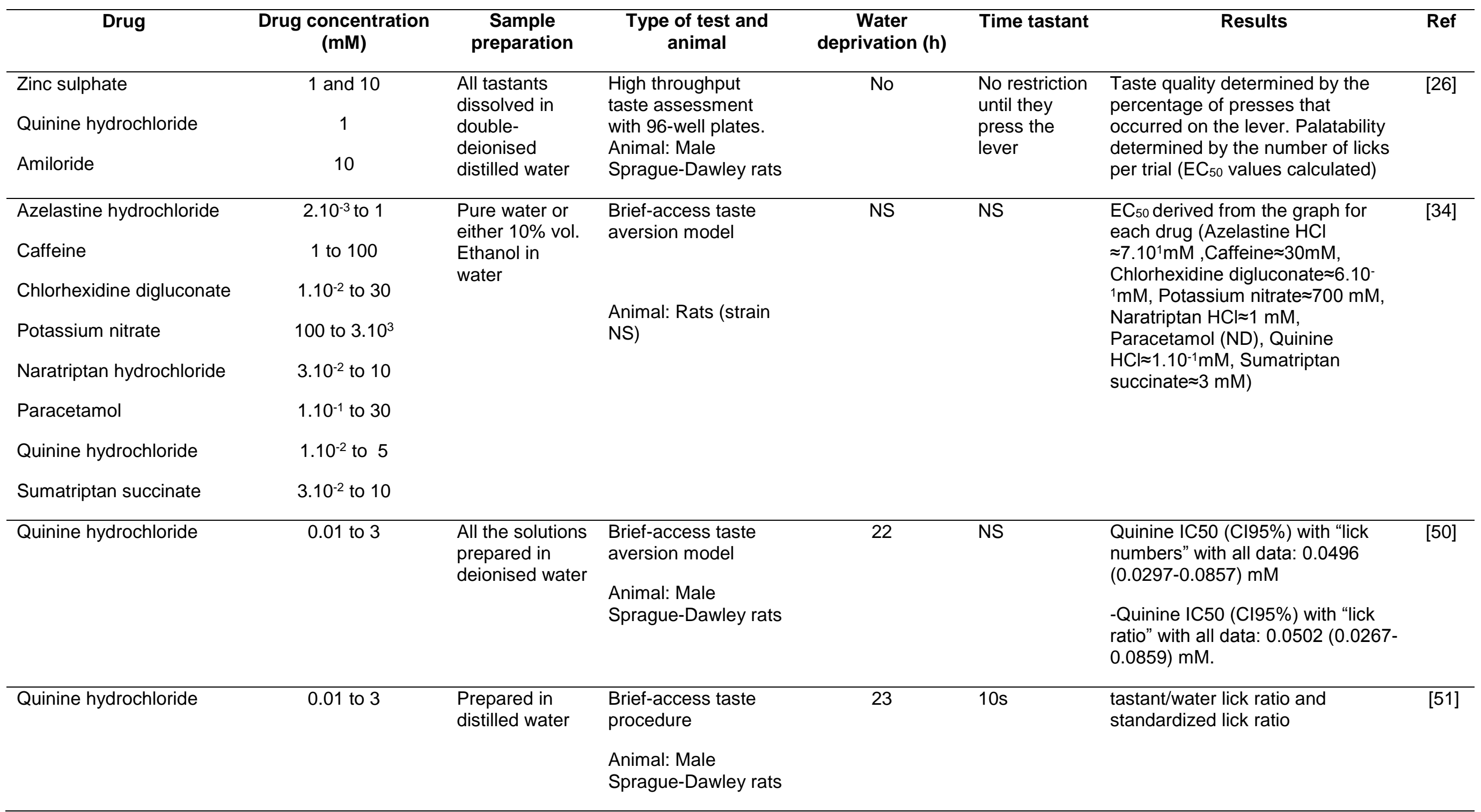




\section{Comparison of common bitter taste assessment methods}

A scoring system was developed based on usability, speed, ability to screen pure active pharmaceutical ingredients or formulations, evidence for correlation with human taste data, potential for validation and cost. It was used to compare between the commonly used bitter taste evaluation tools (Table 4). Based on this literature review, the most useful bitter taste assessment methods were: (1) animal model: brief access taste aversion model (BATA) (score 46) and (2) electronic taste sensing systems: Insent (score 42). 1 and 2 can only be used for assessment of liquids. To assess the taste of solid dosage forms these methods would need to be combined with dissolution/release test conducted at conditions mimicking oral cavity.

Table 4: Scoring method for comparison of common non-human bitter taste assessment tools: from $0=$ Not known, $1=$ low to $5=$ high.

\begin{tabular}{|c|c|c|c|c|c|}
\hline \multirow[t]{2}{*}{ Criterion } & \multicolumn{3}{|c|}{ Animal model } & \multicolumn{2}{|c|}{ Electronic tongue } \\
\hline & BATA & Electrophysiological & Two bottles & Astree & Insent \\
\hline \multicolumn{6}{|l|}{ Usability } \\
\hline $\begin{array}{l}\text { SOP use easy for trained technical staff or } \\
\text { experienced user }\end{array}$ & 3 & 1 & 3 & 4 & 4 \\
\hline Needs a licence or REC approval & 1 & 1 & 1 & 5 & 5 \\
\hline Speed (time from setup to data collection) & 2 & 1 & 1 & 3 & 3 \\
\hline \multicolumn{6}{|l|}{ Ability to screen pure drug/product } \\
\hline Drug, excipients & 5 & 4 & 4 & 5 & 5 \\
\hline $\begin{array}{c}\text { Formulated product (ideally other than } \\
\text { solution e.g. suspension) }\end{array}$ & 3 & 0 & 3 & 3 & 3 \\
\hline Evidence of correlation to in vivo data & 4 & 1 & 3 & 4 & 5 \\
\hline \multicolumn{6}{|l|}{ Potential to validate } \\
\hline Specificity & 5 & 5 & 5 & 5 & 5 \\
\hline Linearity & 5 & 4 & 1 & 4 & 4 \\
\hline Accuracy & 5 & 4 & 3 & 0 & 0 \\
\hline Precision & 4 & 0 & 0 & 1 & 2 \\
\hline Range-quantification limit-detection limit & 3 & 3 & 3 & 1 & 1 \\
\hline \multicolumn{6}{|l|}{ Costs } \\
\hline Initial investment (platform) & 2 & 1 & 2 & 2 & 2 \\
\hline Running costs & 4 & 1 & 4 & 2 & 3 \\
\hline Sum of scores & 46 & 26 & 33 & 39 & 42 \\
\hline
\end{tabular}

\section{Conclusion}

Taste evaluation is very important for assuring the acceptance of medicine to patients. Human taste panels remains the undisputed gold standard method for taste evaluation but this method is hindered, particularly when developing paediatric dosage forms, by safety and ethical concerns (especially when testing drugs with unknown toxicity), and relevance of adult findings as the testing is generally performed in adults for children applications. Several in vitro and in vivo taste evaluation methods have been developed to overcome these obstacles.

Over the past two years, the most common in vitro taste evaluation method was found to be electronic taste sensors mainly either (i) SA402B/ TS-5000z (Insent Inc) or (ii) a-Astree e-sensor (Alpha M.O.S). Most of the published data reported 
good correlation between the human taste panel test and the electronic taste sensing systems. However, in most of these studies methods followed for bitterness prediction and constructing the correlation with human taste data were not always fully described. Electronic sensors give relative taste statement and should be validated with human taste panel tests. Ideally electronic tongues could be used for early screening of taste of pure APIs and optimisation of taste masked preclinical formulations in industry. However until it is demonstrated that electronic tongues can reliably predict bitterness intensity of the compounds which were not used for developing calibration model, the use of this technology is still limited. The taste of final optimised pharmaceutical products should be assessed in human before marketing. In vitro dissolution/ release studies were also common but could not be used alone to determine the taste of pure API or formulated API without knowing human taste thresholds. However, dissolution/ release tests are very important when assessing taste of poorly soluble APIs and coated solid dosage forms. It can be used to support electronic tongues or other in vivo methods in early screening of taste of $\mathrm{API} /$ coated solid dosage forms where it is not feasible to test non liquid forms.

In vivo methods such as behavioural test (brief access taste aversion model, mainly rats) have also been used for taste evaluation of drugs. Several studies showed good correlation with human taste data. This model can be used for early screening of taste of pure API and formulated products. Finally, more than one in vivo and in vitro tool might need to be combined to give accurate taste assessment without need for human testing.

\section{Acknowledgement}

Work completed on behalf of SPaeDD-UK (Smart Paediatric Drug Development UK), a project co-funded by Innovate UK and the contributing companies of AstraZeneca, Bristol Myers Squibb, GlaxoSmithKline, Juniper Pharmaceuticals and Pfizer. http://www.paediatricscienceuk.com.

\section{Reference}

1. Chen, Z., et al., Recent advances in bitterness evaluation methods. Analytical Methods, 2012. 4(3): p. 599-608.

2. Anand, V., et al., The latest trends in the taste assessment of pharmaceuticals. Drug Discovery Today, 2007. 12(5-6): p. 257-265.

3. Woertz, K., et al., A comparative study on two electronic tongues for pharmaceutical formulation development. J Pharm Biomed Anal, 2011. 55(2): p. 272-81.

4. Woertz, K., et al., Taste sensing systems (electronic tongues) for pharmaceutical applications. Int J Pharm, 2011. 417(1-2): p. 256-71.

5. Woertz, K., et al., Performance qualification of an electronic tongue based on ICH guideline Q2. Journal of Pharmaceutical and Biomedical Analysis, 2010. 51(3): p. 497-506.

6. Pein, M., et al., New protocol for alpha Astree electronic tongue enabling full performance qualification according to ICH Q2. Journal of Pharmaceutical and Biomedical Analysis, 2013. 83: p. 157-163.

7. Maniruzzaman, M. and D. Douroumis, An in-vitro-in-vivo taste assessment of bitter drug: Comparative electronic tongues study. Journal of Pharmacy and Pharmacology, 2014. 
8. Maniruzzaman, M., et al., An in-vivo and in-vitro taste masking evaluation of bitter meltextruded drugs. Journal of Pharmacy and Pharmacology, 2014. 66(2): p. 323-337.

9. Ito, M., et al., Bitterness prediction of H-1-antihistamines and prediction of masking effects of artificial sweeteners using an electronic tongue. International Journal of Pharmaceutics, 2013. 441(1-2): p. 121-127.

10. Wang, Y., et al., Sensory evaluation of the taste of berberine hydrochloride using an Electronic Tongue. Fitoterapia, 2013. 86(1): p. 137-143.

11. Preis, M., et al., In-vitro and in-vivo evaluation of taste-masked cetirizine hydrochloride formulated in oral lyophilisates. Int J Pharm, 2015. 491(1-2): p. 8-16.

12. Nakamura, H., et al., The prediction of the palatability of orally disintegrating tablets by an electronic gustatory system. Int J Pharm, 2015. 493(1-2): p. 305-12.

13. Pimparade, M.B., et al., Development of taste masked caffeine citrate formulations utilizing hot melt extrusion technology and in vitro-in vivo evaluations. Int J Pharm, 2015. 487(1-2): p. 167-76.

14. Uchida, T., et al., Evaluation of palatability of 10 commercial amlodipine orally disintegrating tablets by gustatory sensation testing, OD-mate as a new disintegration apparatus and the artificial taste sensor. Journal of Pharmacy and Pharmacology, 2013. 65(9): p. 1312-1320.

15. Yoshida, M., T. Haraguchi, and T. Uchida, Bitterness evaluation of acidic pharmaceutical substances (NSAIDs) using a taste sensor. Chem Pharm Bull (Tokyo), 2014. 62(12): p. 1252-8.

16. Yi, E.J., et al., Preparation of sildenafil citrate microcapsules and in vitro/in vivo evaluation of taste masking efficiency. International Journal of Pharmaceutics, 2014. 466(1-2): p. 286-295.

17. Gittings, S., et al., Dissolution methodology for taste masked oral dosage forms. Journal of Controlled Release, 2014. 173(1): p. 32-42.

18. Pein, M., et al., Taste-masking assessment of solid oral dosage forms-A critical review. International Journal of Pharmaceutics, 2014. 465(1-2): p. 239-254.

19. Kharb, V., et al., Formulation, evaluation and 3(2) full factorial design-based optimization of ondansetron hydrochloride incorporated taste masked microspheres. Pharm Dev Technol, 2014. 19(7): p. 839-52.

20. Lahoti, S.R. and A.B. Jadhav, Formulation of sustained release ondansetron $\mathrm{HCl}$ pediatric suspension using ion exchange resin. International Journal of PharmTech Research, 2013. 5(1): p. 54-62.

21. Stange, U., C. Führling, and H. Gieseler, Taste masking of naproxen sodium granules by fluidbed coating. Pharm Dev Technol, 2014. 19(2): p. 137-147.

22. Tan, Q., et al., Novel taste-masked orally disintegrating tablets for a highly soluble drug with an extremely bitter taste: Design rationale and evaluation. Drug Development and Industrial Pharmacy, 2013. 39(9): p. 1364-1371.

23. Hu, X., et al., Preparation and evaluation of orally disintegrating tablets containing tastemasked microcapsules of berberine hydrochloride. AAPS PharmSciTech, 2013. 14(1): p. 2937.

24. Haraguchi, T., et al., Bitterness evaluation of intact and crushed Vesicare orally disintegrating tablets using taste sensors. Journal of Pharmacy and Pharmacology, 2013. 65(7): p. 980-987.

25. Lou, H., et al., Evaluation of Chlorpheniramine Maleate microparticles in orally disintegrating film and orally disintegrating tablet for pediatrics. Drug Dev Ind Pharm, 2014. 40(7): p. 9108.

26. Palmer, R.K., et al., A high throughput in vivo assay for taste quality and palatability. PLoS One, 2013. 8(8): p. e72391.

27. Gore-Langton, J.K., et al., Measures of the aversive effects of drugs: A comparison of conditioned taste and place aversions. Pharmacol Biochem Behav, 2015. 134: p. 99-105.

28. Gautam, S.H., M.R. Rebello, and J.V. Verhagen, Taste quality and intensity of 100 stimuli as reported by rats: the taste-location association task. Front Behav Neurosci, 2012. 6: p. 19. 
29. Spector, A.C. and S.L. Kopka, Rats fail to discriminate quinine from denatonium: implications for the neural coding of bitter-tasting compounds. J Neurosci, 2002. 22(5): p. 1937-41.

30. Torregrossa, A.M., et al., Examination of the perception of sweet- and bitter-like taste qualities in sucralose preferring and avoiding rats. Physiol Behav, 2015. 140: p. 96-103.

31. Glendinning, J.I., J. Gresack, and A.C. Spector, A high-throughput screening procedure for identifying mice with aberrant taste and oromotor function. Chem Senses, 2002. 27(5): p. 461-74.

32. Hashimoto, K. and A.C. Spector, Extensive lesions in the gustatory cortex in the rat do not disrupt the retention of a presurgically conditioned taste aversion and do not impair unconditioned concentration-dependent licking of sucrose and quinine. Chem Senses, 2014. 39(1): p. 57-71.

33. Devantier, H.R., et al., Quantitative assessment of TRPM5-dependent oral aversiveness of pharmaceuticals using a mouse brief-access taste aversion assay. Behav Pharmacol, 2008. 19(7): p. 673-82.

34. Rudnitskaya, A., et al., Assessment of bitter taste of pharmaceuticals with multisensor system employing 3 way PLS regression. Analytica Chimica Acta, 2013. 770: p. 45-52.

35. Noorjahan, A., B. Amrita, and S. Kavita, In vivo evaluation of taste masking for developed chewable and orodispersible tablets in humans and rats. Pharm Dev Technol, 2014. 19(3): p. 290-5.

36. Kapsimali, M. and L.A. Barlow, Developing a sense of taste. Semin Cell Dev Biol, 2013. 24(3): p. 200-9.

37. Liman, E.R., Y.V. Zhang, and C. Montell, Peripheral coding of taste. Neuron, 2014. 81(5): p. 984-1000.

38. Okada, S., The taste system of small fish species. Biosci Biotechnol Biochem, 2015: p. 1-5.

39. Boyer, B., S. Ernest, and F. Rosa, Egr-1 induction provides a genetic response to food aversion in zebrafish. Front Behav Neurosci, 2013. 7: p. 51.

40. Lvovskaya, S. and D.P. Smith, A spoonful of bitter helps the sugar response go down. Neuron, 2013. 79(4): p. 612-4.

41. Delventhal, R., A. Kiely, and J.R. Carlson, Electrophysiological recording from Drosophila labellar taste sensilla. J Vis Exp, 2014(84): p. e51355.

42. Apostolopoulou, A.A., et al., The neuronal and molecular basis of quinine-dependent bitter taste signaling in Drosophila larvae. Front Behav Neurosci, 2014. 8: p. 6.

43. French, A.S., et al., Dual mechanism for bitter avoidance in Drosophila. J Neurosci, 2015. 35(9): p. 3990-4004.

44. Chu, B., et al., Presynaptic gain control drives sweet and bitter taste integration in Drosophila. Curr Biol, 2014. 24(17): p. 1978-84.

45. Inagaki, H.K., K.M. Panse, and D.J. Anderson, Independent, reciprocal neuromodulatory control of sweet and bitter taste sensitivity during starvation in Drosophila. Neuron, 2014. 84(4): p. 806-20.

46. Chen, Y. and H. Amrein, Enhancing perception of contaminated food through acid-mediated modulation of taste neuron responses. Curr Biol, 2014. 24(17): p. 1969-77.

47. Konig, C., et al., Bitter-sweet processing in larval Drosophila. Chem Senses, 2014. 39(6): p. 489-505.

48. Charlu, S., et al., Acid sensing by sweet and bitter taste neurons in Drosophila melanogaster. Nat Commun, 2013. 4: p. 2042.

49. Miyamoto, T., et al., Identification of a Drosophila glucose receptor using Ca2+ imaging of single chemosensory neurons. PLoS One, 2013. 8(2): p. e56304.

50. Soto, J., et al., Development of a model for robust and exploratory analysis of the rodent brief-access taste aversion data. Eur J Pharm Biopharm, 2015. 
51. Treesukosol, Y., et al., Similarities and differences between "proactive" and "passive" stresscoping rats in responses to sucrose, $\mathrm{NaCl}$, citric acid, and quinine. Chem Senses, 2014. 39(4): p. 333-42. 